\title{
Evaluation of fucoxanthin contents in seaweed biomass by vortex-assisted solid-liquid microextraction using high-performance liquid chromatography with photodiode array detection
}

\author{
N. Nunes ${ }^{\mathrm{a}, \mathrm{b}, *}$, João M. Leça ${ }^{\mathrm{c}, \mathrm{d}}$, Ana C. Pereira ${ }^{\mathrm{c}, \mathrm{e}}$, Vanda Pereira $^{\mathrm{c}, \mathrm{d}}, \mathrm{S}$. Ferraz ${ }^{\mathrm{a}}$, \\ Maria Carmo Barreto ${ }^{\mathrm{f}}$, José C. Marques ${ }^{\mathrm{c}, \mathrm{d}}$, M.A.A. Pinheiro de Carvalho ${ }^{\mathrm{a}}$ \\ ${ }^{a}$ ISOPlexis Genebank, University of Madeira, Campus da Penteada, 9050-290 Funchal, Madeira, Portugal \\ ${ }^{\mathrm{b}}$ UBQ II, Unidade de Bioquímica, Lda. Rua Visconde de Anadia, Edifício Anadia $5^{\circ}$ Andar CC, 9050-020 Funchal, Madeira, Portugal \\ ${ }^{\mathrm{c}}$ Faculty of Exact Sciences and Engineering, University of Madeira, Portugal \\ ${ }^{\mathrm{d}}$ Institute of Nanostructures Nanomodelling and Nanofabrication (I3N), University of Aveiro, Portugal \\ ${ }^{\mathrm{e}}$ Department of Chemical Engineering (3CIEPQPF), University of Coimbra, Portugal \\ ${ }^{\mathrm{f}}$ CE3C-Centre for Ecology, Evolution and Environmental Changes/Azorean Biodiversity Group, Faculty of Sciences and Technology, University of Azores, 9501-801 Ponta \\ Delgada, Portugal
}

\section{A B S T R A C T}

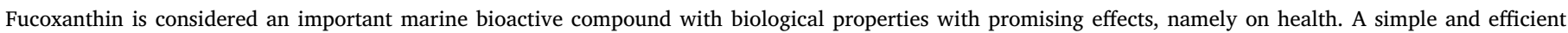

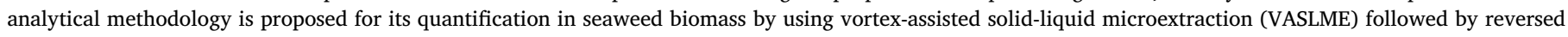

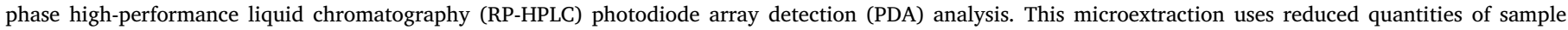

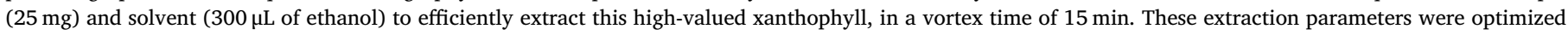

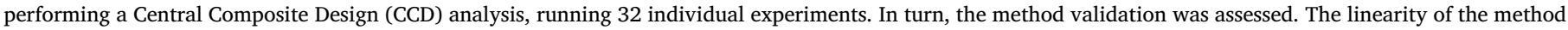

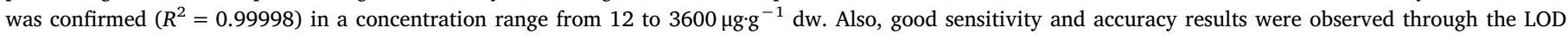

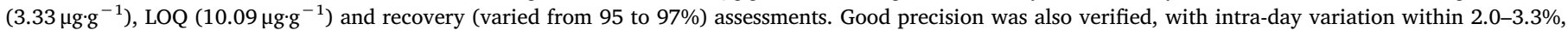

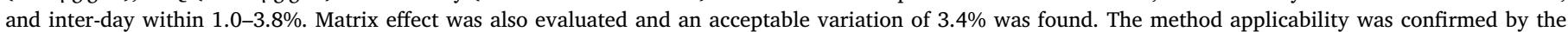

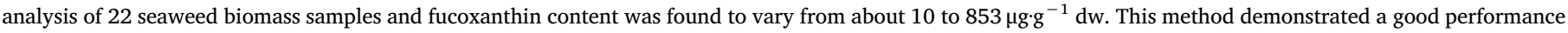
and can be successfully implemented for a rapid, reliable and accurate screening of fucoxanthin in seaweed biomass.

\section{Introduction}

Fucoxanthin is a high-value commercial xanthophyll (about $11 €$ / $\mathrm{mg}$ ) firstly extracted by Willstätter and Page in 1914 from Dictyota, Fucus and Laminaria brown seaweeds, subsequently also found in other brown seaweeds and diatoms (microalgae). It is one of the most abundant carotenoids, estimated to comprise $10 \%$ of the total found in nature [1]. The fucoxanthin content oscillates according to season and life cycle [2]. This carotenoid is linked to chlorophyll $a$ and specific proteins of these marine plants, playing an important role on their light harvesting and photoprotection [3]. Its molecular structure includes an unusual allenic bond and oxygenic functional groups, that together constitute a unique arrangement [4] well developed to capture blue and green photons, predominantly present in deeper ocean waters [5]. Fucoxanthin's distinct molecular structure is also responsible for its exceptional biological activity, particularly for its antioxidant properties, that are mainly related with the free radical scavenging and singlet oxygen species quenching [1]. These properties are quite promising on the prevention and treatment of oxidative stress-related diseases [6]. Additionally, fucoxanthin also demonstrates anti-inflammatory, neuroprotective, antiangiogenic, skin protective, anti-obesity, anti-diabetic, anti-cancer, hepatoprotective, cardiovascular and cerebrovascular protective effects [1,7-10]. Recently, other pharmacological activities have been attributed to fucoxanthin, particularly promising for the therapy of the pulmonary fibrosis [9], cerebral ischemic/reperfusion injury [11], hyperglycemia, hyperlipidemia and insulin resistance [12], glycaemic control [13] and liver cancer [14]. These biological properties suggest its high potential for application in human and animal food, health and cosmetics. Thus, there is high interest not also in fucoxanthin high purity extracts but also in fucoxanthin rich supplements to be used as a natural antioxidant for food or beverages preservation.

Due to its high potential, research developments have been improving the industrial potential to purify fucoxanthin from algae biomass. Macroalgae Saccharina japonica (formerly Laminaria japonica)

\footnotetext{
* Corresponding author at: ISOPlexis Genebank, University of Madeira, Campus da Penteada, 9050-290 Funchal, Madeira, Portugal.

E-mail address: nuno.nunes@staff.uma.pt (N. Nunes).
} 
waste parts have been researched to determine their potential as a commercial-scale fucoxanthin resource using conventional extraction methods [15]. Later, new technological approaches such as pressurized liquid methodology [16] and supercritical $\mathrm{CO}_{2}$ /ethanol extraction [17] have been suggested to obtain larger quantities of extracts rich in fucoxanthin from macro and microalgae and to overcome high production costs, namely reducing solvent-usage and time. Other authors proposed microwave [18] and ultrasound [19] assisted techniques as alternatives. Different extraction conditions have also been investigated, varying the solvent type, solvent-to-solid ratio, extraction time, temperature and the extraction technologies, including maceration, ultrasound-assisted extraction, Soxhlet extraction and pressurized liquid extraction $[3,20]$. Most of these extraction procedures, besides being costly, time-consuming and labour-intensive, often use large amounts of solvent, generating waste and contaminating samples. Also, few studies are devoted to optimize a valid green analytical procedure for the fucoxanthin analysis in algae biomass.

Thus, the main purpose of this work was to develop a simple, fast, cost-effective and environmentally friendly analytical method to rapidly and efficiently assess the fucoxanthin content in seaweed biomass, to determine its potential as a fucoxanthin resource. Therefore, a vortex-assisted solid-liquid microextraction (VASLME) for sample preparation before HPLC-PDA quantification is proposed.

\section{Materials and methods}

\subsection{Chemicals}

All chemicals and standards had a purity grade higher than $95 \%$. Methanol UPLC grade and formic acid were supplied by Panreac (Barcelona, Spain), ethanol by Aga (Portugal) and fucoxanthin standard from Sigma (China). Type 1 ultrapure water was obtained with a Simplicity ${ }^{\circledR}$ UV apparatus from Millipore (Milford, MA, USA).

\subsection{Sample collection and preparation}

Two seaweed biomass sample sets were collected. The first comprises brown macroalgae samples from Madeira archipelago (Portugal) and Galway (Ireland), collected between the intertidal and the subtidal zone up to a 10-meter maximum depth dive. Dictyopteris polypodioides (A.P.De Candolle) J.V. Lamouroux 1809: 332, Dictyota dichotoma (Hudson) J.V.Lamouroux 1809: 42, Halopteris filicina (Grateloup) Kützing 1843: 293, Halopteris scoparia (Linnaeus) Sauvageau 1904: 349, Lobophora variegata (J.V.Lamouroux) Womersley ex E.C.Oliveira 1977: 217, Padina pavonica (Linnaeus) Thivy in W.R.Taylor 1960: 234, Sargassum vulgare C. Agardh 1820: 3 and Zonaria tournefortii (J.V.Lamouroux) Montagne, 1846 were collected in Madeira archipelago (Porto Santo and Madeira Islands). Ascophyllum nodosum (Linnaeus) Le Jolis 1863: 96 and Fucus vesiculosus Linnaeus 1753: 1158 were collected in Galway. These samples were transported in seawater and gently rinsed with filtered fresh water except for Galway seaweed, which were air-dried. Afterwards, a primary drying was applied in which seaweed was frozen at $-35^{\circ} \mathrm{C}$ and freeze-dried under reduced pressure $\left(4 \times 10^{-4} \mathrm{mbar}\right)$, with a cooling trap set at $-56^{\circ} \mathrm{C}$ for 5 days. Samples were milled to 200 mesh particle size, vacuum packed and stored at $-35^{\circ} \mathrm{C}$ until use. These samples were visually identified using the book publications performed by Cabioc'h et al. [21], Braune and Guiry [22], Rodríguez Prieto [23] and Pereira [24]. The second set is composed by 10 samples of beach-cast seaweed collected in the north shore of the island of Gran Canaria (Canary Islands), in "Playa de Las Canteras" from May 29 till October 10, 2017. These were air-dried, milled, packed and sent to our laboratory. The compositional details of these biomasses are presented in Table 1. Seaweed casts are masses of several seaweeds that stay stranded in beaches, affecting tourism, residents, local ecosystems and artisanal fishery. These macroalgae were identified using the book publications of Carrillo and Sansón [25],
Haroun et al. [26] and Espino et al. [27].

\subsection{Vortex Assisted Solid-Liquid Micro-Extraction optimization}

A Central Composite Design (CCD) was implemented to determine the optimum conditions of three parameters of the analytical extraction procedure, namely: sample amount, solvent volume and vortex time. The selected solvent was ethanol at $96 \%$ and extraction performed with a Vortex Genie 2, from Scientific Industries. The brown macroalgae $Z$. tournefortii was used for the optimization and validation assessments. For more information, please consult the Supplementary material.

\subsection{Chromatographic conditions}

A Nexera X2 UHPLC system composed by two binary LC-30AD pumps, a DGU-20 A5 degassing unit, a CTO-20A column oven, a SIL$30 \mathrm{AC}$ autosampler and a PDA detector $(200-800 \mathrm{~nm})$ SPD-M20A was used for chromatographic analysis. The UV/Vis spectrum of fucoxanthin was used for identification and the $454 \mathrm{~nm}$ detection wavelength was used for quantification purposes. A gradient elution with methanol (solution A) and ultra-pure water acidified with $0.1 \%$ of formic acid (solution B) was used at $0.3 \mathrm{~mL} / \mathrm{min}$ flow rate. The gradient started with $6 \mathrm{~min}$ of $20 \%$ solution A, then, it was gradually set up to $90 \%$ in $11 \mathrm{~min}$ changed to $100 \%$ in $1 \mathrm{~min}$ and maintained for $6 \mathrm{~min}$. Finally, solution A was reduced to $5 \%$ in $1 \mathrm{~min}$ and held for $5 \mathrm{~min}$ to prepare the next injection, with a total injection time of $30 \mathrm{~min}$. The mobile phases were previously filtered through a hydrophilic polypropylene $0.2 \mu \mathrm{m}$ pore size membrane filter (Pall Corporation, Ann Arbor). Sample extracts were separated in a reversed phase Sunshell C18 column $(150 \times 2.1 \mathrm{~mm}, 2.6 \mu \mathrm{m})$ from ChromaNik Technologies Inc. (Osaka, Japan), thermostated at $30^{\circ} \mathrm{C}$, with an injection volume of $1 \mu \mathrm{L}$. All samples were extracted in triplicate and injected twice.

\subsection{Method validation}

The optimized methodology was validated, assessing linearity, sensitivity, matrix effects, selectivity, precision (repeatability and reproducibility) and accuracy. Linearity was calculated based on linear regression analysis, through correlation coefficient $\left(\mathrm{R}^{2}\right)$. Sensitivity was evaluated by the limit of detection (LOD) and limit of quantification (LOQ) according to Eqs. (1) and (2), respectively, where $\sigma$ is the standard deviation of the y-intercept and $b$ the curve slope.

$\mathrm{LOD}=3.3 \frac{\sigma}{\mathrm{b}} 3 \sigma / \mathrm{b}$

$\mathrm{LOQ}=10 \frac{\sigma}{\mathrm{b}}$

For the calibration curve, eight working standard solutions were prepared within $12-3600 \mu \mathrm{g} \cdot \mathrm{g}^{-1} \mathrm{dw}$ concentration range, by spiking ethanol with the fucoxanthin standard solution.

Matrix effects were also evaluated, based on the ratio between two slope curves: one with the response of the direct injection of fucoxanthin standard working solutions (curve 1) and the other obtained from the extracts of the seaweed biomass ( $Z$. tournefortii) spiked with the fucoxanthin standard working solutions (curve 2), as described by Matuszewski [28] (Eq. (3)).

$\% \mathrm{ME}=\left[\frac{(\text { slope of calibration curve } 1-\text { slope of calibration curve } 2)}{\text { slope of calibration curve } 1}\right]$

These analyses intended to determine if the seaweed matrix (ME matrix effect) had influence on the fucoxanthin extraction.

The method selectivity was verified by checking the absence of interferences at the fucoxanthin retention time of the chromatograms of all samples and standard solutions. 
Table 1

Composition of seaweed beach cast samples collected between May 29 and October 10, 2017, in "Playa de Las Canteras", Gran Canaria.

\begin{tabular}{|c|c|c|}
\hline Seaweed code & Prospection date & Seaweed composition \\
\hline 1 & 29-May-2017 & Dictyota sp. (32\%), H. incurva (57\%), L. variegata (10.7\%) and others $(0.3 \%)$ \\
\hline 2 & 23-Jun-2017 & A. taxiformis (16.6\%), C. barbata (8.4\%), Dictyota sp. (30.6\%), Jania sp. (30.5\%) and L. variegata (13.9\%) \\
\hline 3 & 26-Jun-2017 & A. taxiformis (50\%), Dictyota sp. $(41.6 \%)$ and $H$. scoparia $(8.4 \%)$ \\
\hline 4 & 12-July-2017 & A. taxiformis (45\%), Dictyota sp. (21\%), L. variegata (25\%) and H. scoparia (9\%) \\
\hline 5 & 20-July-2017 & A. taxiformis (34.8\%), Dictyota sp. (39.1\%), Jania sp. (4.3\%) and L. variegata (21.8\%) \\
\hline 6 & 8-Aug-2017 & A. taxiformis (30\%), Dictyota sp. (36\%), L. variegata (24\%) and H. scoparia (10\%) \\
\hline 7 & 21-Aug-2017 & A. taxiformis (28\%), Dictyota sp. (42\%), L. variegata (22\%) and H. scoparia (8\%) \\
\hline 8 & 18-Sep-2017 & A. taxiformis (33.8\%), C. barbata (14.5\%), Dictyota sp. (22.6\%), Laurencia sp. (0.5\%) and L. variegata (28.6\%) \\
\hline 9 & 6-Oct-2017 & A. taxiformis $(23.8 \%)$, C. barbata $(22.2 \%)$, Dictyota sp. $(22.2 \%)$ and $L$. variegata $(31.8 \%)$ \\
\hline 10 & 10-Oct-2017 & C. barbata (10\%), Dictyota sp. (20\%), Jania sp. (25\%) and L. variegata (45\%) \\
\hline
\end{tabular}

Repeatability and reproducibility were assessed by intra and interday analysis, respectively, of $Z$. tournefortii sample and two ethanol standard solutions of fucoxanthin ( 480 and $2400 \mu \mathrm{g} \cdot \mathrm{g}^{-1} \mathrm{dw}$ ). The assessment of repeatability was obtained through the variation coefficient of ten successive extractions of these samples. The reproducibility was evaluated by the analysis of five extractions of the same samples in three different days, in a time span of 10 days. These results were expressed in percentage to the relative standard deviation (\%RSD).

Accuracy was determined through the evaluation of a recovery study, spiking a macroalgae sample (Lobophora variegata) at three different fucoxanthin concentrations $\left(24,480\right.$ and $2400 \mu \mathrm{g} \cdot \mathrm{g}^{-1} \mathrm{dw}$ ). Recovery was calculated according to Eq. (4) where SWS is the measured fucoxanthin concentration in a spiked sample, SW is the measured concentration in the sample and $S$ is the concentration of fucoxanthin added to the sample.

Recovery $(\%)=\frac{\text { SWS }- \text { SW }}{\text { S }} \times 100(\%)$

Finally, the method was applied to 10 different seaweeds (12 samples) and 10 beach-cast seaweeds (10 samples) containing different species of brown seaweed in its composition, in order to confirm the applicability of the proposed methodology for the determination of fucoxanthin in seaweed biomass.

\subsection{Extract stability}

The extract stability was evaluated at 0,5 and 10 days after extraction to determine if these extracts could be considered stable. $Z$. tournefortii extracts at two fucoxanthin concentrations, 480 and $2400 \mu \mathrm{g} \cdot \mathrm{g}^{-1} \mathrm{dw}$, were used for this assay. These were kept at $10^{\circ} \mathrm{C}$ in amber vials. Additionally, two ethanol fucoxanthin standard solutions at same concentration were also tested.

\subsection{Statistical analysis}

Samples were evaluated using two replicas and three injections, being expressed as mean of six measurements \pm standard deviation. Definitive Screening Design (DSD) for design matrix and subsequent data analysis (model estimation and optimization) was achieved using the $\mathrm{JMP}^{\circledast}$ ver. 11.1.0 (32-bit) (SAS Institute Inc.).

\section{Results and discussion}

\subsection{Vortex Assisted Solid-Liquid Micro-Extraction optimization}

Methanol, acetone and ethanol are the most common solvents used for the extraction of marine pigments (Ragumaran et al. [19]). In this study, methanol was not considered due to its inherent toxicity (class 2 solvent). Kim et al. [3] tested different solvents (water, ethyl acetate, acetone and $n$-hexane) for the extraction of fucoxanthin from the diatom Phaeodactylum tricornutum and reported that the best extraction yield was obtained when high purity grade ethanol was used. Although ethanol (class 3 solvent - low toxicity) is not as widely used as acetone (also class 3 solvent) for the extraction of microalgae pigments, it has revealed greater yield for fucoxanthin extraction [3]. For all these reasons ethanol was chosen as the extraction solvent to develop the experimental layout. With the purpose of developing a green extraction procedure, solvent microvolumes were considered. In order to assist the microextraction, ultrasound and vortex were investigated. Tests with ultrasound bath revealed lack of repeatability, therefore, it was decided to proceed with vortex assistance. The use of small quantities of sample was also intended.

The design matrix to determine the best extraction conditions for fucoxanthin was established by a Central Composite Design (CCD), with three factors, volume of ethanol $(\mu \mathrm{L})$, vortex time (min) and sample amount (mg) at three levels, with center points. For more information about the design, please consult the Supplementary material.

\subsection{Method validation}

The VASLME followed by HPLC-PDA method was validated for the rapid determination of fucoxanthin content in seaweed biomass. The results are expressed in Table 2. The validation parameters assessed were linearity, sensitivity, matrix effects, selectivity, precision and accuracy, after determining the optimal extraction conditions of fucoxanthin.

No matrix effect was observed, \%ME was $3.4 \%$. Therefore, the calibration curve adopted was the one performed by spiking fucoxanthin (Fx) stock solution in ethanol, according to Eq. (5).

Fx area $=2,306,667 \times$ Fx concentration $\mu \mathrm{g} \bullet \mathrm{g}^{-1}+6595$

A good correlation coefficient of R2 $=0.99998$ was found, supporting the method linearity. Also, excellent sensitivity was obtained, $\mathrm{LOD}=3.33 \mu \mathrm{g} \cdot \mathrm{g}^{-1}$ and LOQ $=10.09 \mu \mathrm{g} \cdot \mathrm{g}^{-1}$. These values are quite lower than the values typically found in macroalgae (about

Table 2

Validation results for VASLME methodology to quantify fucoxanthin in seaweed.

\begin{tabular}{lll}
\hline & Parameter & Result \\
\hline Linearity & Linear regression $(\mathrm{y}=\mathrm{mx}+\mathrm{b})$ & $2,306,667 \mathrm{x}+6595$ \\
& Linear concentration range & $12-3600 \mu \mathrm{g} \cdot \mathrm{g}^{-1}$ \\
& $\mathrm{R}^{2}$ & 0.99998 \\
Sensitivity & $\mathrm{LOD}\left(\mu \mathrm{g} \cdot \mathrm{g}^{-1}\right)$ & 3.33 \\
& $\mathrm{LOQ}\left(\mu \mathrm{g} \cdot \mathrm{g}^{-1}\right)$ & 10.09 \\
Accuracy & $\mathrm{Recovery}$ & $\%$ \\
& $\mathrm{SW}+24 \mu \mathrm{g} \cdot \mathrm{g}^{-1}$ & 96 \\
& $\mathrm{SW}+480 \mu \mathrm{g} \cdot \mathrm{g}^{-1}$ & 95 \\
& $\mathrm{SW}+2400 \mu \mathrm{g} \cdot \mathrm{g}^{-1}$ & 97 \\
Precision & Intra-day (\% RSD) & $2.0-3.3$ \\
& Inter-day (\% RSD) & $1.0-3.8$ \\
\hline
\end{tabular}

All determinations were the result of two replicas each injected three times. LOD - limit of detection; LOQ - limit of quantification; SW - seaweed; RSD relative standard deviation. 
Table 3

Seaweed samples for fucoxanthin yield testing.

\begin{tabular}{|c|c|c|c|}
\hline Seaweed & Collection site & Prospection date & $\begin{array}{l}\text { Fucoxanthin content } \\
\left(\mu \mathrm{g} \cdot \mathrm{g}^{-1} \mathrm{dw} \pm \mathrm{SD}\right)\end{array}$ \\
\hline A. nodosum & $\begin{array}{l}\text { Galway } \\
\text { (Ireland) }\end{array}$ & Jun/2018 & $21.6 \pm 0.9$ \\
\hline D. dichotoma & Porto Santo & Mar/2017 & $12.2 \pm 0.4$ \\
\hline D. dichotoma & Madeira & Aug/2018 & $514 \pm 5$ \\
\hline D. polypodioides & Madeira & Aug/2018 & $597 \pm 30$ \\
\hline F. vesiculosus & $\begin{array}{c}\text { Galway } \\
\text { (Ireland) }\end{array}$ & Jun/2018 & $22 \pm 1$ \\
\hline H. filicina & Porto Santo & Mar/2017 & $17.3 \pm 0.3$ \\
\hline H. scoparia & Madeira & Jan/2016 & $10.1 \pm 0.3$ \\
\hline L. variegata & Porto Santo & Mar/2017 & $40.9 \pm 0.8$ \\
\hline P. pavonica & Madeira & July/2016 & $10.2 \pm 0.3$ \\
\hline S. vulgare & Madeira & Jun/2017 & $400 \pm 14$ \\
\hline Z. tournefortii & Madeira & Aug/2016 & $852 \pm 12$ \\
\hline Z. tournefortii & Madeira & July/2017 & $381 \pm 3$ \\
\hline
\end{tabular}

Data are mean \pm standard deviation in micrograms of fucoxanthin per $1 \mathrm{~g}$ of algae on a dry weight basis (dw). All determinations were the result of two replicas each injected three times. dw - dry weight; SD - standard deviation.

$100-1000 \mathrm{mg} \cdot \mathrm{g}^{-1} \mathrm{dw}$ ) [29]. The method also revealed good precision: 2 to $3.3 \%$ of variation in intra-day analyses and 1 to $3.8 \%$ for the interday analysis. Additionally, the results of the recovery study ranged between 95 and 97\%, as summarized in Table 2, demonstrating the accuracy of the method.

After assessing the figures which resulted from the Response Surface Methodology (RSM) assessed in this work and are presented as Supplementary material, fucoxanthin was quantified in 22 samples of algae biomass. The fucoxanthin contents (Tables 3 and 4) were found to vary between $10.1 \pm 0.3$ and $852 \pm 12 \mu \mathrm{g} \cdot \mathrm{g}^{-1} \mathrm{dw}$, which are within the calibration range. Fig. 1 shows the typical chromatograms (Fx retention time at $19.9 \mathrm{~min})$ of a standard solution $\left(240 \mu \mathrm{g} \cdot \mathrm{g}^{-1} \mathrm{dw}\right)$ and a seaweed biomass sample (brown algae), confirming the method selectivity. It also revealed that the variation between sample replicates never exceeded the $7 \%$, even at levels close to LOQ.

\subsection{Extract stability}

Sample extracts kept at $10{ }^{\circ} \mathrm{C}$, enclosed in amber vials, were tested for stability and considered suitable due to the low variation detected between initial ( 0 days), middle ( 5 days) and the end ( 10 days) of the assay. For $Z$. tournefortii, the variation of fucoxanthin content was $0.8 \%$ and $0.3 \%$ for 5 and 10 days, respectively. The fucoxanthin ethanolic solution at $480 \mu \mathrm{g} \cdot \mathrm{g}^{-1} \mathrm{dw}$ was found to vary $1.3 \%$ and $4.3 \%$ in 5 and 10 days respectively. For the fucoxanthin solution with $2400 \mu \mathrm{g} \cdot \mathrm{g}^{-1}$ concentration, the variation was found to be $0.7 \%$ in both dates.

These results indicate that ethanolic extracts of fucoxanthin are

Table 4

Seaweed beach casts tested for fucoxanthin concentration.

\begin{tabular}{ccc}
\hline $\begin{array}{l}\text { Seaweed beach cast } \\
\text { code }\end{array}$ & Prospection date & $\begin{array}{l}\text { Fucoxanthin concentration }\left(\mu \mathrm{g} \cdot \mathrm{g}^{-1}\right. \\
\mathrm{dw} \pm \mathrm{SD})\end{array}$ \\
\hline 1 & 29-May-2017 & $20.3 \pm 1.3$ \\
2 & 23-Jun-2017 & $14.2 \pm 0.6$ \\
3 & 26-Jun-2017 & $13,2 \pm 0,51$ \\
4 & 12-July-2017 & $33.3 \pm 0.8$ \\
5 & 20-July-2017 & $27.6 \pm 1.7$ \\
6 & 8-Aug-2017 & $32.6 \pm 1.2$ \\
7 & 21-Aug-2017 & $19.6 \pm 1.0$ \\
8 & 18-Sep-2017 & $49.4 \pm 2.0$ \\
9 & 6-Oct-2017 & $22.9 \pm 0.6$ \\
10 & 10-Oct-2017 & $28.4 \pm 1.1$ \\
\end{tabular}

Data are mean \pm standard deviation in micrograms of fucoxanthin per $1 \mathrm{~g}$ of algae on a dry weight basis (dw). All determinations were the result of two replicas each injected three times. dw - dry weight; SD - standard deviation. stable in the 10 days after sample extraction, regardless of its concentration. Thus, an accurate evaluation of the fucoxanthin concentration in seaweed biomass can be obtained at least for 10-day period at $10^{\circ} \mathrm{C}$ and light protected. This result is very important not only for performing the simultaneous extraction of multiple samples and stock before HPLC analysis, but also for eventual industrial applications.

This methodology enables to accurately assess the fucoxanthin content in macroalgae biomass, using small quantities of biomass, allowing sample shipping to dedicated laboratories and perform several extractions at once, reducing extraction time. Stability of the extract is favourable since sample sets could be extracted and analysed with precision within 10 days when kept at $10{ }^{\circ} \mathrm{C}$ in amber vials. Table 5 summarizes some fucoxanthin analysis methods. These are compared for the quantity of algal resource needed, solvent and volume used for extraction, health and environmental concerns relating the use of these solvents, extraction methodology and analysis apparatus. The resulting ratio (solvent/algal quantity) presented by other works are usually greater than this work, using higher solvent quantities to extract fucoxanthin from selected samples, producing more waste. Some of these solvents are health concerns or environmentally aggressive, being necessary safer and greener options. Also, simplicity is achieved when smaller quantities of algae, solvent and fewer steps are needed to perform fucoxanthin analysis, resulting in larger number of samples, which can be handled at the same time. Performing the methodology described in this work, it is possible to analyse 50 individual vials in a 3 day period.

\subsection{Fucoxanthin content in seaweed biomass}

Table 3 reports the evaluation results of 12 samples of 10 different marine brown macroalgae species. The fucoxanthin contents varied significantly between samples, from $10.1 \pm 0.3 \mu \mathrm{g} \cdot \mathrm{g}^{-1} \mathrm{dw}$ to $852 \pm 12 \mu \mathrm{g} \cdot \mathrm{g}^{-1} \mathrm{dw}$. Samples with high fucoxanthin concentrations, varying from $400 \pm 14$ to $852 \pm 12 \mu \mathrm{g} \cdot \mathrm{g}^{-1} \mathrm{dw}$ (Z. toutournefortii, $D$. polypodioides, $D$. dichotoma, $S$. vulgare), were all collected in Madeira Island seas. These species are comparable to those found by Jaswir et al. [30] in Sargassum aquifolium (as Sargassum binderi) and Sargassum ilicifolium (as Sargassum duplicatum), collected in the Straits of Malacca, near Port Dickson (Malaysia), between 730 and $1010 \mu \mathrm{g} \cdot \mathrm{g}^{-1} \mathrm{dw}$ of fucoxanthin and higher contents than those reported by Kim et al. [3] in Ecklonia bicyclis (as Eisenia bicyclis) collected in South Korea $\left(260 \mu \mathrm{g} \cdot \mathrm{g}^{-1} \mathrm{dw}\right)$. On the other hand, the majority of the brown macroalgae samples evaluated exhibited low fucoxanthin contents (lower than $40.9 \pm 0.8 \mu \mathrm{g} \cdot \mathrm{g}^{-1} \mathrm{dw}$ ). It is interesting to notice that this result cannot be attributed to the species, since the same species revealed different concentration levels at different locations ( $D$. dichotoma) and collection dates ( $Z$. tournefortii). This result might also be related to seasonality, as it has been recently published [6]. Table 4 presents the screening results of 10 beach-cast seaweeds, composed by different brown seaweeds and others (Table 1), sampled in "Playa de Las Canteras", Gran Canaria within the studied collecting period (May 29 and October 10, 2017). The fucoxanthin content was found to vary between $13.2 \pm 0.5 \mu \mathrm{g} \cdot \mathrm{g}^{-1} \mathrm{dw}$ in sample 3 (June 26,2017 ) and $49 \pm 2 \mu \mathrm{g} \cdot \mathrm{g}^{-1}$ $\mathrm{dw}$ in sample 8 (September 18, 2017). The fucoxanthin levels of this biomass resource varies along the year and are even comparable to some brown macroalgae samples collected in Madeira Islands and Galway. These algae wastes can be valorised as a relevant bioresource of high-valued bio-compounds for eventual industrial applications, namely through the implementation of biorefinery strategies.

\section{Conclusion}

A simple and reliable analytical method was successfully optimized and validated to quickly quantify fucoxanthin in seaweed biomass, using reduced amounts of sample and extraction solvent. Simultaneous 


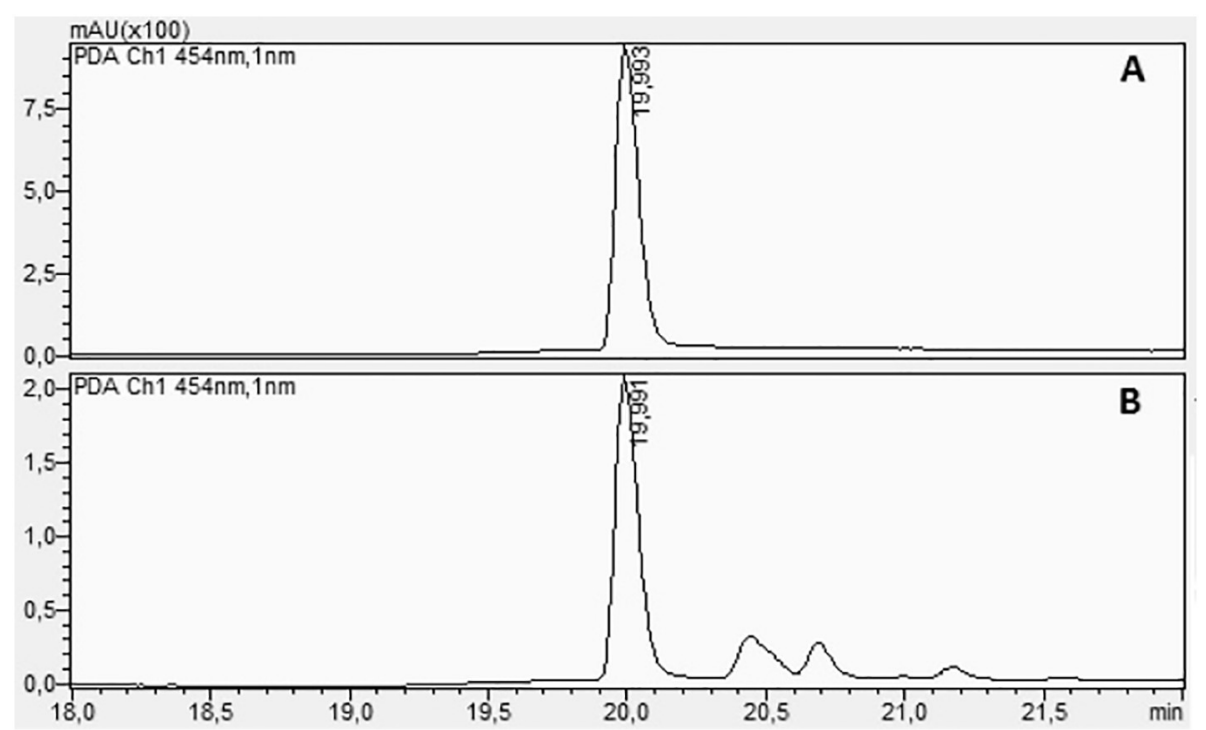

Fig. 1. Chromatograms of a fucoxanthin standard solution of $240 \mu \mathrm{g} \cdot \mathrm{g}^{-1} \mathrm{dw}$ (A) and a brown seaweed sample (B).

Table 5

Summarized methods for fucoxanthin analysis.

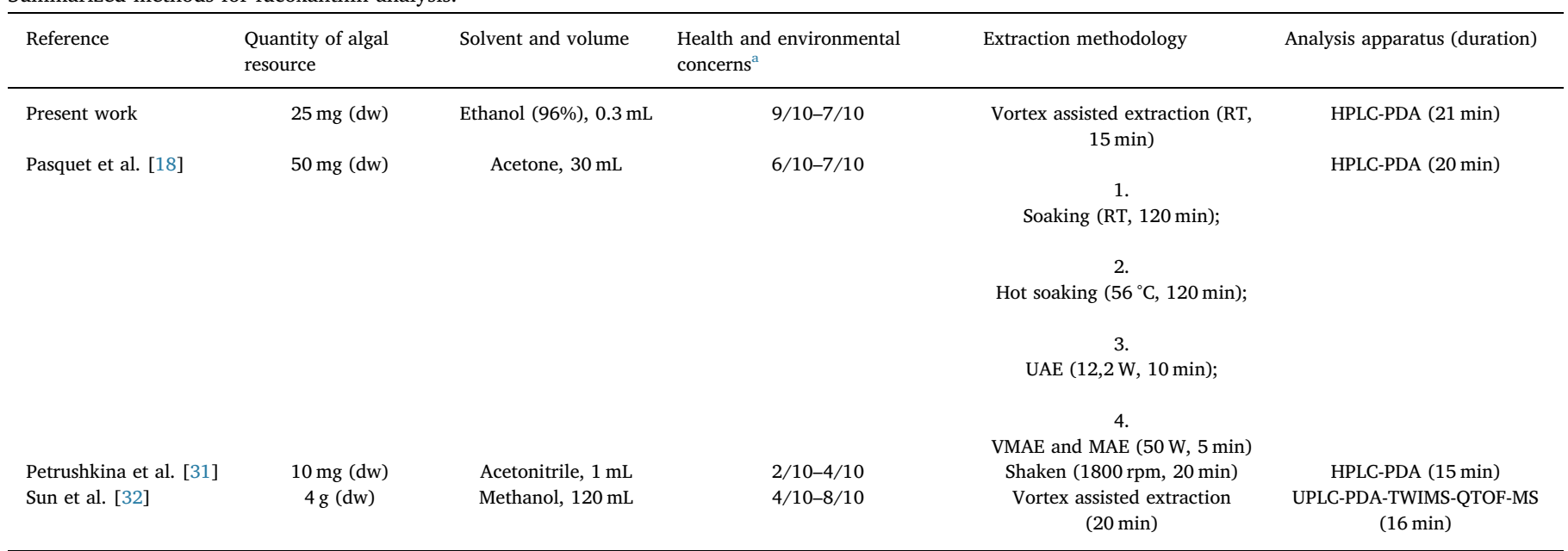

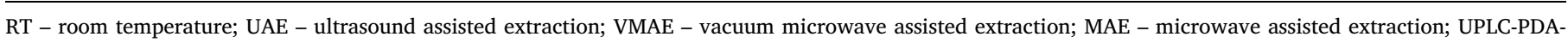

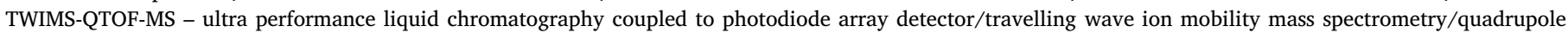
time-of-flight mass spectrometry.

${ }^{\text {a }}$ Retrieved from Curzons et al. [33], higher numbers are preferable.

seaweed biomass VASLME can be performed prior to RP-HPLC-PDA analysis, which takes $30 \mathrm{~min}$. CCD was crucial to optimize the fucoxanthin extraction yield, pointing out that $25 \mathrm{mg}$ of sample with $300 \mu \mathrm{L}$ of ethanol and vortexed for $15 \mathrm{~min}$ are the best experimental combination for the proposed sample preparation procedure. Good results were obtained for all the validation parameters, particularly in terms of sensitivity (LOQ $=10.09 \mu \mathrm{g} \cdot \mathrm{g}^{-1}$ ) and precision (maximum variation of $3.8 \%$ ). Ethanolic extracts are stable at least for a 10 -day period at $10{ }^{\circ} \mathrm{C}$ and light protected, allowing the simultaneous extraction of multiple samples and stock them before HPLC analysis. The method proved to be an accurate tool for the evaluation of the fucoxanthin concentration in seaweed biomass, as it was demonstrated by the analysis of 22 samples. Fucoxanthin concentration was found to vary from about 10 to $852 \mu \mathrm{g} \cdot \mathrm{g}^{-1} \mathrm{dw}$.

Samples collected in Madeira presented the highest contents (400-852 $\mu \mathrm{g} \cdot \mathrm{g}^{-1} \mathrm{dw}$ ), namely those from Z. tournefortii, D. polypodioides, $D$. dichotoma and $S$. vulgare brown macroalgae. In beach-cast seaweeds from Gran Canaria the fucoxanthin levels $\left(<49 \mu \mathrm{g} \cdot \mathrm{g}^{-1} \mathrm{dw}\right)$ are comparable to some brown macroalgae samples collected in
Madeira Islands and Galway. This information can contribute to the development of sustainable strategies to valorise these algae wastes as a relevant bioresource of high-valued bio-compounds for eventual industrial applications.

\section{Declaration of author's contribution}

1) Nuno Nunes contribution included analysis and interpretation of the data and wrote the article.

2) João M. Leça also performed the analysis and interpretation of data.

3) Ana C. Pereira contributed with statistical expertise and obtaining of funding.

4) Vanda Pereira contributed with drafting of the article and critical revision of the article for important intellectual content.

5) Sónia Ferraz provided the study materials, obtained funding and revised it critically.

6) Maria do Carmo Barreto performed a critical revision of the article for important intellectual content and obtaining of funding.

7) José C. Marques performed a critical revision of the article for 
important intellectual content and Final approval of the article.

8) M.A.A. Pinheiro de Carvalho also performed a critical revision of the article for important intellectual content and final approval of the article.

Also, Nuno Nunes, Vanda Pereira, José C. Marques and M.A.A. Pinheiro de Carvalho take full responsibility for the integrity of the work as a whole.

\section{Statement of informed consent, human/animal rights}

No conflicts, informed consent, human or animal rights applicable.

\section{Declaration of Competing Interest}

The authors declare that they have no conflicts of interest.

\section{Acknowledgments}

This work was financially supported by DemoBlueAlgae "Desenvolvimento de metodologias e optimização dos processos de cultivo e processamento de macroalgas para a indústria e economia azul” PROCiência 2020 (M1420-01-0247-FEDER000002); MACBIOBLUE "Proyecto demostrativo y de transferencia tecnológica para ayudar a las empresas a desarrollar nuevos produtos y procesos en el ambito de la Biotecnología Azul de la Macaronesia" (MAC/1.1b/ 086), Interreg MAC 2014-2020. Nuno Nunes (PhD studentship), João M. Leça (PhD studentship), Vanda Pereira (Post Doc fellowship) and Ana C. Pereira (Post Doc fellowship) are thankful to the Agência Regional para o Desenvolvimento da Investigação Tecnologia e Inovação (ARDITI) for the financial support through their grants in the scope of the project M1420-09-5369-FSE-000001. Also, the authors present their acknowledgment to DRCT (Azores Regional Government) for co-financing, the Portuguese National Funds, through FCT - Fundação para a Ciência e a Tecnologia, and as applicable co-financed by the FEDER within the PT2020 Partnership Agreement by funding the cE3c center (UID/BIA/00329/2013) and to DRCT for funding Azorean Biodiversity Group.

\section{Appendix A. Supplementary data}

Supplementary data to this article can be found online at https:// doi.org/10.1016/j.algal.2019.101603.

\section{References}

[1] K. Miyashita, M. Hosokawa, Fucoxanthin in the management of obesity and its related disorders, J. Funct. Foods 36 (2017) 195-202, https://doi.org/10.1016/j.jff. 2017.07.009.

[2] E.M. Balboa, E. Conde, A. Moure, E. Falqué, H. Domínguez, In vitro antioxidant properties of crude extracts and compounds from brown algae, Food Chem. (2013), https://doi.org/10.1016/j.foodchem.2012.11.026.

[3] S.M. Kim, Y.J. Jung, O.N. Kwon, K.H. Cha, B.H. Um, D. Chung, C.H. Pan, A potential commercial source of fucoxanthin extracted from the microalga Phaeodactylum tricornutum, Appl. Biochem. Biotechnol. 166 (2012) 1843-1855, https://doi.org/ 10.1007/s12010-012-9602-2.

[4] J. Peng, J.P. Yuan, C.F. Wu, J.H. Wang, Fucoxanthin, a marine carotenoid present in brown seaweeds and diatoms: metabolism and bioactivities relevant to human health, Mar. Drugs 9 (2011) 1806-1828, https://doi.org/10.3390/md9101806.

[5] L. Caron, D. Douady, M. Quinet-Szely, S. De Goër, C. Berkaloff, Gene structure of a chlorophyll a/c-binding protein from a brown alga: presence of an intron and phylogenetic implications, J. Mol. Evol. 43 (1996) 270-280, https://doi.org/10. 1007/BF02338835.

[6] G.A. Fariman, S.J. Shastan, M.M. Zahedi, Seasonal variation of total lipid, fatty acids, fucoxanthin content, and antioxidant properties of two tropical brown algae (Nizamuddinia zanardinii and Cystoseira indica) from Iran, J. Appl. Phycol. 28 (2016) 1323-1331, https://doi.org/10.1007/s10811-015-0645-y.

[7] A.G. Gutiérrez-Rodríguez, C. Juárez-Portilla, T. Olivares-Bañuelos, R.C. Zepeda, Anticancer activity of seaweeds, Drug Discov. Today (2017), https://doi.org/10. 1016/j.drudis.2017.10.019.

[8] S. Kraan, Pigments and minor compounds in algae, Functional Ingredients From
Algae for Foods and Nutraceuticals, Elsevier, 2013, pp. 205-251, , https://doi.org/ 10.1533/9780857098689.1.205.

[9] S.Y. Ma, W.S. Park, D.S. Lee, G. Choi, M.J. Yim, J.M. Lee, W.K. Jung, S.G. Park, S.K. Seo, S.J. Park, I.Y. Han, Y.H. Choi, I.W. Choi, Fucoxanthin inhibits profibrotic protein expression in vitro and attenuates bleomycin-induced lung fibrosis in vivo, Eur. J. Pharmacol. 811 (2017) 199-207, https://doi.org/10.1016/j.ejphar.2017.06. 022 .

[10] H. Zhang, Y. Tang, Y. Zhang, S. Zhang, J. Qu, X. Wang, R. Kong, C. Han, Z. Liu, Fucoxanthin: a promising medicinal and nutritional ingredient, Evid. Based Complement. Alternat. Med. 2015 (2015) 723515, , https://doi.org/10.1155/ 2015/723515.

[11] L. Hu, W. Chenb, F. Tian, C. Yuan, H. Wang, H. Yue, Neuroprotective role of fucoxanthin against cerebral ischemic/reperfusion injury through activation of Nrf2/ HO-1 signaling Lixun, Biomed. Pharmacother. 106 (2018) 1484-1489, https://doi. org/10.1016/j.biopha.2018.07.088.

[12] Y. Zhang, W. Xu, X. Huang, Y. Zhao, Q. Ren, Z. Hong, M. Huang, X. Xing, Fucoxanthin ameliorates hyperglycemia, hyperlipidemia and insulin resistance in diabetic mice partially through IRS-1/PI3K/Akt and AMPK pathways, J. Funct. Foods 48 (2018) 515-524, https://doi.org/10.1016/j.jff.2018.07.048.

[13] N. Zaharudin, D. Staerk, L.O. Dragsted, Inhibition of $\alpha$-glucosidase activity by selected edible seaweeds and fucoxanthin, Food Chem. 270 (2019) 481-486, https:// doi.org/10.1016/j.foodchem.2018.07.142.

[14] S.C. Foo, F.M. Yusoff, M.U. Imam, J.B. Foo, N. Ismail, N.H. Azmi, Y.S. Tor, N.M.H. Khong, M. Ismail, Increased fucoxanthin in Chaetoceros calcitrans extract exacerbates apoptosis in liver cancer cells via multiple targeted cellular pathways, Biotechnol. Rep. 21 (2019), https://doi.org/10.1016/j.btre.2018.e00296.

[15] K. Kanazawa, Y. Ozaki, T. Hashimoto, S.K. Das, S. Matsushita, M. Hirano, T. Okada, A. Komoto, N. Mori, M. Nakatsuka, Commercial-scale preparation of biofunctional fucoxanthin from waste parts of brown sea algae Laminaria japonica, Food Sci. Technol. Res. 14 (2008) 573-582, https://doi.org/10.3136/fstr.14.573.

[16] Y.F. Shang, S.M. Kim, W.J. Lee, B. Um, Pressurized liquid method for fucoxanthin extraction from Eisenia bicyclis (Kjellman) Setchell, 111 (2011), pp. 237-241, https://doi.org/10.1016/j.jbiosc.2010.10.008.

[17] B. Gilbert-López, J.A. Mendiola, J. Fontecha, L.A.M. van den Broek, L. Sijtsma, A. Cifuentes, M. Herrero, E. Ibáñez, Downstream processing of Isochrysis galbana: a step towards microalgal biorefinery, Green Chem. 17 (2015) 4599-4609, https:// doi.org/10.1039/C5GC01256B.

[18] V. Pasquet, J. Chérouvrier, F. Farhat, V. Thiéry, J. Piot, J. Bérard, R. Kaas, B. Serive, T. Patrice, J. Cadoret, L. Picot, I.L. Pba, C.I. De Nantes, Study on the microalgal pigments extraction process: performance of microwave assisted extraction, Process Biochem. 46 (2011) 59-67, https://doi.org/10.1016/j.procbio.2010.07.009.

[19] V. Raguraman, S.A. L, D. Mubarakali, G. Narendrakumar, R. Thirugnanasambandam, R. Kirubagaran, N. Thajuddin, Unraveling rapid extraction of fucoxanthin from Padina tetrastromatica: Purification, characterization and biomedical application, 73 (2018) 211-219, https://doi.org/10.1016/j. procbio.2018.08.006.

[20] M. Wen, S. Lim, M. Tan, Y. Chew, K.W. Kong, S.W. Yan, Application of two-level full factorial design for the extraction of fucoxanthin and antioxidant activities from Sargassum siliquosum and Sargassum polycystum, J. Aquat. Food Prod. Technol. 27 (2018) 446-463, https://doi.org/10.1080/10498850.2018.1448918.

[21] J. Cabioc'h, J.Y. Floc'h, A. Le Toquin, C.F. Boudouresque, A. Meinesz, M. Verlaque, Guide des algues des mers d'Europe: Manche/Atlantique-Méditerranée, Delachaux et Niestlé, 1992.

[22] W. Braune, M.D. Guiry, Seaweeds: A Colour Guide to Common Benthic Green, Brown and Red Algae of the World's Oceans, A.R.G. Gantner Verlag KG, 2011.

[23] C. Rodríguez Prieto, Guía de las macroalgas y fanerógamas marinas del Mediterráneo Occidental, Omega, 2013.

[24] L. Pereira, Edible Seaweeds of the World, CRC Press Taylor \& Francis Group, 2016.

[25] J. Carrillo, M. Sansón, Algas, hongos y fanerógamas marinas de las Islas Canarias: clave analítica, Servicio de Publicaciones, Universidad de La Laguna, 1999.

[26] R. Haroun, M.C. Gil-Rodríguez, W. Wildpret, Plantas marinas de las Islas Canarias, Canseco, 2003.

[27] F. Espino, A. Boyra, F. Tuya, R.J. Haroun, Guía visual de especies marinas de Canarias, Oceanográfica, 2006.

[28] B.K. Matuszewski, Standard line slopes as a measure of a relative matrix effect in quantitative HPLC-MS bioanalysis, J. Chromatogr. B Anal. Technol. Biomed. Life Sci. 830 (2006) 293-300, https://doi.org/10.1016/j.jchromb.2005.11.009.

[29] L.-J. Wang, Y. Fan, R. Parsons, G.-R. Hu, P.-Y. Zhang, F.-L. Li, L.-J. Wang, Y. Fan, R.L. Parsons, G.-R. Hu, P.-Y. Zhang, F.-L. Li, A rapid method for the determination of fucoxanthin in diatom, Mar. Drugs 16 (2018) 33, https://doi.org/10.3390/ md16010033.

[30] I. Jaswir, D. Noviendri, H.M. Salleh, K. Miyashita, Fucoxanthin extractions of brown seaweeds and analysis of their lipid fraction in methanol, Food Sci. Technol. Res. 18 (2012) 251-257.

[31] M. Petrushkina, E. Gusev, B. Sorokin, N. Zotko, A. Mamaeva, A. Filimonova, M. Kulikovskiy, Y. Maltsev, I. Yampolsky, E. Guglya, V. Vinokurov, Z. Namsaraev, D. Kuzmin, Fucoxanthin production by heterokont microalgae, Algal Res. 24 (2017) 387-393, https://doi.org/10.1016/j.algal.2017.03.016.

[32] P. Sun, C.C. Wong, Y. Li, Y. He, X. Mao, T. Wu, Y. Ren, F. Chen, A novel strategy for isolation and purification of fucoxanthinol and fucoxanthin from the diatom Nitzschia laevis, Food Chem. 277 (2019) 566-572, https://doi.org/10.1016/j. foodchem.2018.10.133.

[33] A.D. Curzons, D.C. Constable, V.L. Cunningham, Solvent selection guide: a guide to the integration of environmental, health and safety criteria into the selection of solvents, Clean Techn. Environ. Policy 1 (2002) 82-90, https://doi.org/10.1007/ s100980050014. 